February 2017

\title{
Protest Responses and Willingness to Accept: Ecosystem Services Providers' Preferences towards Incentive-Based Schemes
}

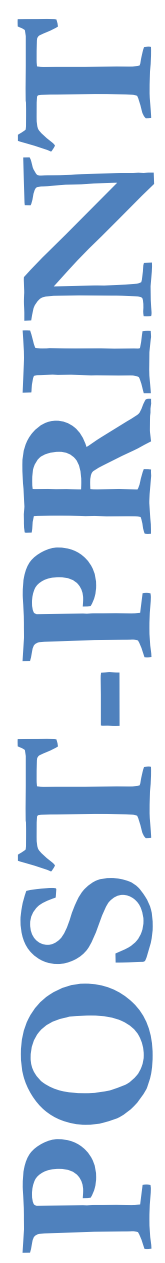

\author{
Villanueva, A.J. \\ Glenk, K. \\ Rodríguez-Entrena, M.
}

Paper accepted to be published in

Journal of Agricultural Economics

Editorial: John Wiley \& Sons, Inc. ISSN: 1477-9552

http://dx.doi.org/10.1111/1477-9552.12211

This research is co-financed by the Spanish Ministry of Economics and Competitiveness (MINECO), the National Institute for Agricultural and Food Research and Technology

(INIA) and the European Regional Development Fund (ERDF) through the projects SUSTANOLEA (P10-AGR5892) and MERCAOLI (RTA2013-00032-00-00). 


\title{
Protest Responses and Willingness to Accept: Ecosystem Services Providers' Preferences towards Incentive-Based Schemes
}

\author{
Anastasio J. Villanueva, Klaus Glenk and Macario Rodríguez-Entrena ${ }^{1}$
}

[Original submitted May 2016, Revision received October 2016, Accepted November 2016]

ABSTRACT. The identification and treatment of protest responses in stated preference surveys has long been subject to debate. We analyse protest responses while investigating ecosystem services providers' preferences for incentive-based schemes. We use a choice experiment for olive farmers' preferences for agri-environmental scheme participation in southern Spain. Our two main objectives are: first, to identify and discuss a range of possible motives for protest responses that emerge in a WTA context; second, we analyse the impact on WTA estimates of censoring serial non-participation linked to protest or high compensation requirements (very high takers). Using a random parameter logit model in WTA space, we find that the inclusion or exclusion of serial non-participants in the analysis can have a significant impact on marginal and total WTA estimates. Based on the findings, the paper makes recommendations on how to reduce the incidence of protest responses through survey design, regarding the identification of protesters as opposed to very high takers, and regarding the treatment of both groups of respondents for WTA estimation.

KEYWORDS: Protest response; Willingness to accept; Payments for ecosystem services; Agrienvironmental schemes; Choice experiment; Olive farmers; Spain

JEL classifications: Q18, Q58.

\footnotetext{
Anastasio J. Villanueva is the contact author (ajvillanueva@uco.es) and is a Research Fellow in the Department of Agricultural Economics, University of Córdoba (UCO), Spain. Klaus Glenk is the "Sustainable Ecosystems" team leader, Scotland's Rural College (SRUC), Land Economy, Environment \& Society Group, Edinburgh, UK. Macario Rodríguez-Entrena is a Senior Researcher in the Department of Agricultural Economics, Institute of Agricultural and Fisheries Research and Training (IFAPA), and an Assistant Professor in UCO, Córdoba, Spain. This research is co-financed by the Spanish Ministry of Economics and Competitiveness (MINECO), the National Institute for Agricultural and Food Research and Technology (INIA) and the European Regional Development Fund (ERDF) through the projects SUSTANOLEA (P10-AGR5892) and MERCAOLI (RTA2013-00032-00-00). The first and the last author acknowledge the support provided by Andalusian Institute of Agricultural Research and Training (IFAPA) and the European Social Fund (ESF) within the Operative Program of Andalusia 2007-2013 through postdoctoral training programs. Klaus Glenk acknowledges support by the Scottish Government Rural Affairs and the Environment Portfolio Strategic Research Programmes 2011-2016 (Theme 3: Land Use), and 2016-2021 (Theme 2: Productive and Sustainable Land Management and Rural Economies). Our thanks are due to two anonymous reviewers and Prof. David Harvey for valuable comments on an earlier draft.
} 


\section{Introduction}

It is well-known that some respondents to stated preference surveys do not engage in the hypothetical market to reveal their preferences (Halstead et al., 1992). Commonly, these people are considered to be 'protesters' since they reject (protest against) aspects of the constructed market scenario (Meyerhoff et al., 2014). However, it is challenging to clearly distinguish between responses that reflect protest motives and responses that actually reflect respondents' preferences (Meyerhoff and Liebe, 2006; Meyerhoff et al., 2012). In willingness to pay (WTP) contexts, the issue is demonstrated by the difficulty of differentiating protest responses from true or 'genuine' zero responses (Barrio and Loureiro, 2013). Correctly identifying protest responses matters, because their inclusion or omission in the analysis can affect welfare estimates (Halstead et al., 1992; Strazzera et al., 2003).

The identification and subsequent treatment of protest responses has received much attention in the stated preference literature (Strazzera et al., 2003; Dziegielewska and Mendelsohn, 2007; Meyerhoff and Liebe, 2006, 2010; Barrio and Loureiro, 2013; Söderberg and Barton, 2014). However, all of these studies concern consumers' WTP for changes in the provision of environmental goods and services. The issue of protest responses has, to the best of our knowledge, not yet been systematically investigated in the context of willingness to accept (WTA), although an increasing number of studies analyse preferences of ecosystem service (ES) providers towards incentive-based schemes (Horne, 2006; Layton and Siikamäki, 2009; Espinosa-Goded et al., 2010; Christensen et al., 2011; Barr and Mourato, 2014; Peterson et al., 2015). These studies usually estimate WTA of ES providers for enrolment in incentivebased schemes, with the underlying assumption being that providers' choices about participation depend on the specific scheme characteristics. In the past decade, choice experiments (CE), and to a lesser extent contingent valuation approaches (CV), have been extensively applied in the context of agri-environmental schemes (AES) in Europe (Horne, 2006; Espinosa-Goded et al., 2010; Christensen et al., 2011; Broch and Vedel, 2012; BeharryBorg et al., 2013), and payments for ecosystem services schemes (PES) in the United States (Cooper, 1997; Matta et al., 2009; Peterson et al., 2015), and other parts of the World (Barr and Mourato, 2014; Mulatu et al., 2014).

Few WTA studies investigating incentive-based schemes consider protest responses, and even then the constitution of protest responses is seldom if ever analysed systematically, 
applying different criteria for identifying protest patterns. As a consequence, the current literature does not provide any coherent guidance on identifying protest responses in WTA contexts. To our knowledge, there is also no empirical evidence of the impact of protest responses on ES providers' WTA for contract attributes of incentive-based schemes. We aim to provide insights into both the identification and analysis of protest responses in WTA assessments.

We investigate possible reasons for protest behaviour and propose effective means of identifying them in WTA studies related to incentive-based scheme design. We use data from a case study on olive growers' preferences towards AES design in Andalusia (southern Spain) (Villanueva et al., 2015) to analyse the impact of inclusion or omission of protest responses on WTA. We use a random parameter logit model in WTA space, and also use a sample selection bivariate probit model to investigate factors determining serial non-participation.

\section{Characterising non-participation decisions of ecosystem services providers: protest and very high taking}

While the identification of protest responses in WTP formats typically consists of distinguishing protest bids from 'true' zero bids (Barrio and Loureiro, 2013; Söderberg and Barton, 2014), protest in WTA is mainly concerned with distinguishing protest behaviour from 'very high taking' (Ferreira and Gallagher, 2010). Very high takers (VHT) are respondents whose WTA for the good on offer exceeds the highest bid level offered in closed-ended contingent valuation formats, or the highest compensation level offered in any alternative of a CE. In the context of CE aimed at assessing land managers' participation in incentive-based schemes, serial non-participation (choosing the opt-out or status quo alternative in all choice tasks of a CE) therefore reflects either an aversion to making trade-offs in general (protest) or very high compensation requirements (VHT).

Land managers are typically the focus for stated preference studies assessing ES providers' WTA for participating in incentive-based schemes. Assuming rational behaviour, a land manager chooses to participate in a scheme if the expected benefits of doing so outweigh the costs.

Apart from the compensation offered, benefits include expectations regarding a scheme's short term or long term impact on production efficiency, and also may reflect 
individual satisfaction from contributions to environmental quality. Potential aspects that affect expectations on costs include transaction costs associated with participation, or management costs associated with technology change (Pannell, 2008), as well as the opportunity costs of participation. Further, farmers' risk attitude may affect how costs and benefits are perceived and therefore influence their decision to participate (Schilizzi and Latacz-Lohmann, 2016). Incentive-based scheme alternatives for inclusion in stated preference studies directly control for benefits derived from compensation payments. Apart from that, scheme alternatives may be designed in a way that entail transaction costs (e.g. reporting requirements), allowing the researcher to observe elements of transaction costs over and above those incurred from participation in general. Choice of management prescriptions may affect transaction costs and also influence perceived benefits in terms of productivity or environmental performance. However, it is difficult to isolate these effects through the experimental design of the study. Actual costs (especially opportunity costs) and benefits of the farmer therefore often remain unobserved.

So long as the compensation payment is sufficiently high, all rational land managers would be expected to participate in the scheme (i.e. making trade-offs between attributes of scheme participation and compensation requirements). In this case (all are rational profit maximisers), serial non-participation would typically represent "very high taking". The only exception is the potential for strategic behaviour by some land managers, provided that they perceive that their responses will influence agency decisions (i.e. if the respondents perceive the survey as consequential, as highlighted by Carson and Groves, 2007). However, not all land managers may be entirely driven by profit maximization. Non-profit-based motives (which can reflect self-interest or not) can have an important impact on a land manager's decision making (e.g. Gasson, 1973; Burton, 2004; Barnes et al., 2011). Social interest and stewardship motives can affect the evaluation of a scheme's benefits (Chouinard et al., 2008). If a proposed scheme's benefits and its institutional design are in conflict with beliefs and values, land managers may not participate regardless of the compensation amount offered. For example, land managers who value independent decision making may oppose to being constrained to a narrowly defined set of management prescriptions regardless of the incentive (Kuhfuss et al., 2015) and potential efficiency gains in production. 
These considerations imply that a serial non-participant can either be a VHT or a protester depending on the reasons for non-participation. In practice, the boundaries between protesters and VHT will be blurred. However, it is still possible to distinguish between motives for non-participation that are more likely to be either related to protest behaviour or to being a VHT. This would then offer a possibility to deal with both reasons for serial nonparticipation in the analysis.

Protesters are typically considered to be outside the market and should thus be omitted from the analysis used to derive WTA estimates. Because their inclusion may bias WTA estimates, it is important to report their incidence and how they have been identified. This equally applies to VHT, whose treatment prior to analysis is less clear, since their compensation threshold for participation is greater than the greatest amount offered in the payment vector. VHT are therefore not willing to make trade-offs within the constraints of the proposed schemes. One may argue that they should be retained in the sample because their choices reflect their true preferences. Moreover, inclusion of VHT may have a significant effect on estimates of mean total WTA since their preferences are mostly captured through the ASC. However, it may equally be argued that it is not appropriate to assume that VHT hold the same preferences as participants over the stated contract scheme attributes given that trade-offs over attributes (and thus the consequences) are not observed. In any case, as for protesters, the incidence of VHT should also be reported, which is something that many studies fail to do (both for protest responses and serial non-participation in general). This can be observed in Table S1.1 (see on-line Appendix S1), which provides a detailed and comprehensive overview of WTA studies in the context of incentive-based schemes focused on ES provision. Only 12 out of 54 studies listed report any information on protest responses, and just five of these provide a more detailed account on the identification, incidence and treatment of protest responses and serial non-participation.

There is no consensus about the identification of protest responses amongst those studies which report it. Our focus is on discriminating protest responses from VHT, but the criteria for allocation to each group vary considerably between studies. They include, for example, dissent with the proposed scheme (e.g. "it has nothing to do with real farming") (Christensen et al., 2011), lack of trust in institutions (Lienhoop and Brouwer, 2015), misunderstanding or lack of information (Broch and Vedel, 2012), and whether respondents 
state that they do not want to be constrained in their choice of farming practices irrespective of the level of payment (Kuhfuss et al., 2015). Barr and Mourato (2014) consider 'irrational choice' to be indicative of a protest response, but do not detail what constitutes an irrational choice. Other criteria for identifying protesters used in the reviewed literature may equally reflect responses of VHT. Such criteria include, for example, whether respondents find all the hypothesised alternatives unattractive at the level of monetary compensation offered (Layton and Siikamäki, 2009). All the WTA studies that report information on protest responses exclude them from further analysis (Table S1.1). All of them except Kuhfuss et al. (2015) use open-ended questions to inquire on the reasons for serial non-participation, which is a common way of identifying protest responses in WTP approaches (Arrow et al., 1993; Bateman et al., 2002). Our literature review clearly suggests that the identification and treatment of protest responses deserves further attention, especially concerning supply-side environmental valuation studies using WTA formats.

\section{Method}

Random parameter logit (RPL) model in willingness to accept (WTA) space

Using CE data on farmers' participation in an AES, we investigate the effect of inclusion or omission of serial non-participants, i.e. protesters and VHT, on WTA for participating in schemes aimed at enhancing the provision of ES. To do so, we compare WTA estimates derived from three different samples: (i) the whole sample (Total); (ii) the sample excluding protesters (No_protest); and (iii) the sample excluding protesters and VHT (Participants). For analysing the repeated choices between two alternatives of a scheme and a non-participation alternative ('status quo'), random parameter logit models (RPL) with an additional error component in WTA space are used. The modelling approach is based on random utility theory, with a utility function $U$ for farmer $n$ and alternative $i$ in choice task $t$ :

$$
U_{\text {nit }}=\alpha_{n}{ }^{\prime} p_{\text {nit }}+\beta_{n}{ }^{\prime} x_{\text {nit }}+\vartheta_{\text {nit }}+\varepsilon_{\text {nit }}
$$

where $p$ and $x$ are monetary and non-monetary attributes of the experimental design, $\alpha$ and $\beta$ are parameters to be estimated, and $\varepsilon$ is the random error term, which is assumed to be identically and independently distributed (iid) and related to the choice probability with a Gumbel distributed error term. To account for the fact that respondents may treat the hypothetical AES alternatives $(A, B)$ as being systematically different to the status quo (Scarpa 
et al., 2005), an additional error component $\vartheta_{\text {nit }}$ (distributed with $\mathrm{N}\left(0, \sigma^{2}\right)$ ) was included in the utility function, capturing the error variance shared by both $A$ and $B$.

In RPL models, heterogeneity across respondents is introduced by allowing $\alpha_{n}$ and $\beta_{n}$ to deviate from the population means following a random distribution. The unconditional choice probability of respondent n's sequence of choices ( $y_{n}$ over $T_{n}$ choice tasks) is:

$$
\operatorname{Pr}\left(y_{n} \mid \alpha_{n}, \beta_{n}, \vartheta\right)=\iint \prod_{t_{1}=1}^{T_{n}} \frac{\exp \left(\alpha_{n}^{\prime} p_{n i t}+\beta_{n}^{\prime} x_{n i t}\right)}{\sum_{j=1}^{J} \exp \left(\alpha_{n}^{\prime} p_{n j t}+\beta_{n}^{\prime} x_{n j t}\right)} f\left(\eta_{n i} \mid \Omega\right) \phi\left(\vartheta \mid 0, \sigma^{2}\right) d \eta_{n i} d \vartheta \text { [2] }
$$

where $f\left(\eta_{n i} \mid \Omega\right)$ is the joint density of parameter vector for monetary and $K$ non-monetary attributes $\left[\alpha_{n}, \beta_{n 1}, \beta_{n 2}, \ldots, \beta_{n K}\right], \eta_{n i}$ is the vector comprised of the random parameters and $\Omega$ denotes the parameters (namely the mean and variance) of these distributions. $\phi(\cdot)$ the normal density function for the error component. This integral does not have a closed form and thus requires approximation through simulation (Train, 2003). Our simulations are based on 1,000 draws using Modified Latin Hypercube Sampling.

All choice models are estimated in WTA space (Train and Weeks, 2005), which allows the distributions of WTA to be estimated directly and hence avoids issues with calculating WTA as the ratio of two random distributions. The parameters of monetary and non-monetary attributes are assumed to follow lognormal and normal distributions, respectively. An alternative specific constant specified for the status quo alternative ASC $_{\mathrm{sO}}$, assumed to follow a normal distribution) was also included in the model, representing observed utility not captured by the attributes.

We use the complete combinatorial test suggested by Poe et al. (2005) to test for differences in WTA estimates between the three samples (Total; No_protest; Participants). Total WTA for participation in alternative variants of an AES is estimated following Hanemann (1984). Total WTA therefore provides important information on the average compensation requirements for participation depending on scheme characteristics. The $\mathrm{ASC}_{\mathrm{s} Q}$ was included in these estimates, because it captures the utility difference between not participating in the scheme and entering a contract at baseline attribute levels for dummy coded categorical attributes and status quo levels for continuously coded attributes. Importantly, the constant also captures the utility difference between zero compensation in case of non-participation and the lowest compensation level offered in the contract alternatives. The sign of the ASCsa therefore also depends on whether or not the expected cost of scheme participation is -on 
average across the sample- outweighed by the benefits associated with the lowest level of compensation offered in the experiment. Compared to non-participation, farmers can either expect to be worse off by scheme participation at the lowest compensation amount (positive effect on $\mathrm{ASC}_{\mathrm{sa}}$ ) or already expect to benefit from participation even at the lowest amount on offer (negative effect on $\mathrm{ASC}_{\mathrm{sa}}$ ). Also, the inclusion of the $\mathrm{ASC}_{\mathrm{sQ}}$ is recommended if it can plausibly carry a behavioural interpretation (Adamowicz et al., 1998). In our context, there may be factors influencing the farmers' decision to participate in AES over and above the scheme attributes. Such factors may reflect barriers to uptake (Falconer, 2000), including transaction costs (Pannell, 2008), but also positive attitudes towards participating in AES, for example because farmers perceive AES as financially rewarding, as highlighted by Hynes and Garvey (2009).

\section{Sample selection bivariate probit model}

Following the identification of Protesters and VHT (see below), we model the decision process as a sequence of two decisions, using a sample selection bivariate probit model (Greene, 2003). First, farmers decide whether to protest against the valuation exercise $(Y 1=0)$ or not $(Y 1=1)$. Then, those respondents not protesting further decide whether to participate in the AES on offer ( $Y 2=1$, which includes all the farmers who chose to participate at least in one choice situation, thus representing Participants) or not ( $\mathrm{Y} 2=0$, which includes all the nonprotesting farmers who always chose the status quo alternative, thus representing VHT). We use the bivariate model, because we expect that the residuals of the expression explaining the dependent variables (Y1 and $\mathrm{Y} 2$ ) will be correlated.

\section{Data}

Our data come from a CE survey of olive farmers in Andalusia, Spain. Olive trees are the main crop grown in the region, covering more than 1.5 million hectares or $48 \%$ of the farmland. Olive grove systems have a great potential for improvement in the provision of environmental public goods. According to Villanueva et al. (2014), biodiversity, soil fertility, mitigation of climate change, and visual quality of the landscape are the four public goods with the greatest enhancement potential. However, both previous and current AES target only a few specific olive grove areas within the region. This motivated our investigation of the implementation of 
AES aimed at increasing the provision of public goods from a wide range of olives groves in the region.

\section{Attributes}

Six attributes were used in the CE. Three attributes were linked to agricultural management aimed at improving environmental public good provision (biodiversity, soil conservation, carbon sequestration, and landscape amenity) (Barranco et al., 2008; Stoate et al., 2009; Villanueva et al., 2014), two attributes to policy design and a final attribute specifies the level of compensation payments.

Two of the agricultural management attributes focus on soil management, in particular on the area covered by cover crops and the management of that area. The two levels of the attribute Cover crop area (CCAR) of $25 \%$ and $50 \%$ of the olive grove area (CCAR-25\% and CCAR50\%) were set based on Gómez-Limón and Arriaza (2011) and expert knowledge. Cover crop management (CCMA) has two levels: unconstrained (CCMA-Free) and constrained management (CCMA-Constr) with respect to tillage and herbicide use, with the latter being a condition in former AES available to olive growers.

For the attribute Ecological focus areas (EFA), levels were set at zero and $2 \%$ of the olive grove plots covered by EFA (EFA-0\% and EFA-2\%). The first level is equivalent to the current requirement for receiving single farm payments for permanent crops. Considering the current lack of land qualifying as EFA in Andalusian olive groves and the difficulties of increasing the share of EFA in permanent crops (Gómez-Limón and Arriaza, 2011), the second level was set to be lower than the $5 \%$ of EFA to be provided by arable farms as part of the greening component of single farm payments in the Common Agricultural Policy (CAP).

Collective participation (COLLE) and monitoring (MONI) are the two scheme design attributes included in the CE. Collective contracts represent a promising way of reducing transaction costs (mainly public) while increasing the environmental effectiveness of policy instruments (Uthes and Matzdorf, 2013). Participation in the scheme was offered either as a collective or as an individual. For participation to be considered collective, a group of at least five farmers whose farms are located in the same municipality have to sign the same AES contract. With regards to MONI, previous literature shows that the level of monitoring influences farmers' preferences towards AES (e.g. Broch and Vedel, 2012). The two levels set for $\mathrm{MONI}$ are $5 \%$ and $20 \%$ of olive grove farms monitored (MONI-5\% and MONI-20\%, 
respectively) over the contract length of 5 years. $5 \%$ is the typical monitoring level of CAP measures, while the higher level represents a considerable increase over current practice.

Finally, with regard to the payment attribute (PAYM), four levels were established according to payments in a previous AES (Sub-Measure 7) available to olive growers (€204$286 /$ ha per year). Two levels ( $€ 200 /$ ha and $€ 300 /$ ha) were set in line with these payments, while two further levels (€100/ha and $€ 400 /$ ha) were set as minimum and maximum payments.

\section{Experimental design and data collection}

A fractional factorial design that is optimal in the differences (Street and Burgess, 2007) was used to create a manageable number of choice sets, reducing from all possible combinations (1924) to 192 profiles (D-efficiency=91.3\%). The 192 choice sets were divided into 24 blocks of eight choice sets each. Each farmer answered one block. In each choice set, farmers were asked to choose between two alternatives of $A E S$ and a status quo alternative, representing non-participation. Figure 1 shows an example of a typical choice set.

A multi-stage sampling procedure was employed. In the first stage, five agricultural districts ${ }^{2}$ in Andalusia were selected as primary sampling units from a total of 52 . The sampled districts account for $31.0 \%$ of Andalusian olive groves. In the next stage, 10 villages/towns located in each of the sampled districts were selected as secondary sampling units using a random route procedure. Finally, in each village 6-8 face-to-face interviews were conducted intercepting farmers in various public places and various times of the day ${ }^{3}$. The interviews were carried out between October 2013 and January 2014. Of a total of 330 interviews, 327 complete responses were obtained. In terms of key farm characteristics such as average yield and farmers' age, level of education and farm-labour time, the sample mirrors farm characteristics obtained in a previous benchmarking survey of Gómez-Limón and Arriaza (2011), who used the same farm conceptualization ${ }^{4}$. With respect to size, large farms seem to

\footnotetext{
${ }^{2}$ Campiña Norte and La Loma (province of Jaen), La Sierra and Campiña Alta (province of Cordoba), and Norte (province of Malaga).

${ }^{3}$ There is no register of farmers that would have allowed random sampling since the conceptualization of "olive grove farm" is different in our study compared to the official statistics (e.g. CAyP, 2008), as we consider farm as a single decision-making entity regardless of its legal personality. Farmers usually live in towns with their farms (and plots) being spread over nearby areas.

${ }^{4}$ We ran t-tests ( $\chi^{2}$ for dichotomous variables) to compare our sample characteristics to those of that survey.
} 
be slightly overrepresented relative to the benchmarking survey, although this may be explained by the on-going structural change in the region ${ }^{5}$.

Amongst the respondents, serial non-participants were carefully scrutinised in order to distinguish protesters from VHT based on an analysis of an open-ended question on the reasons for serial non-participation. Serial non-participants who stated protest reasons were considered to be protesters, while the remaining participants were considered to be VHT. We did not collect information on perceived consequentiality; however, the interviewers did not detect strategic behaviour that would indicate a lack of consequentiality.

Figure 1

Example of a typical choice set

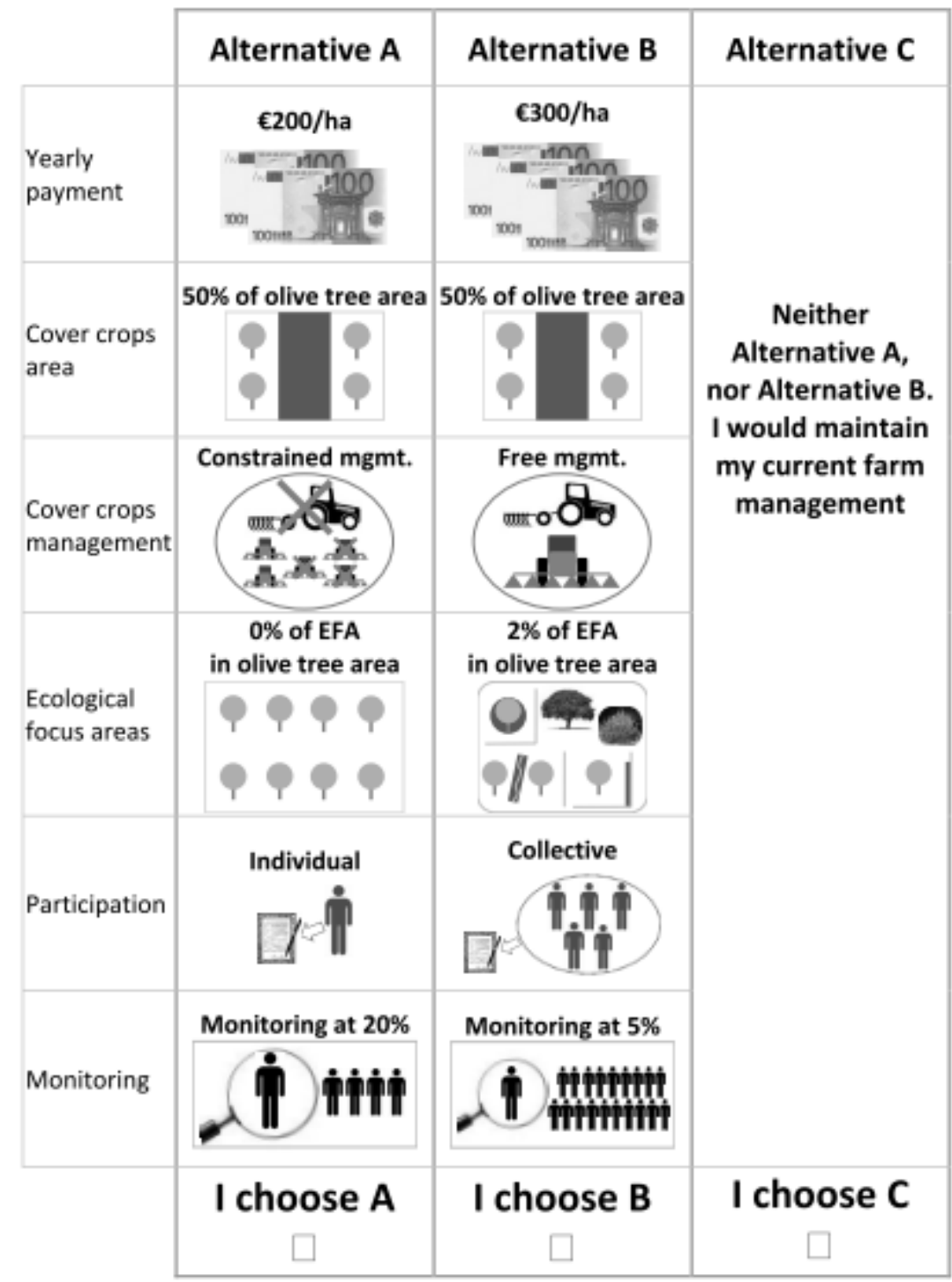

\footnotetext{
${ }^{5}$ The sampling method may have led to a slight overrepresentation of large farms. However, this is unlikely to explain the differences between the two surveys as both used a very similar sampling method.
} 


\section{Results}

\section{Identification of protest responses}

Of the total of 327 complete responses used for analysis, 67 were serial non-participants (20.5\% of the total sample); that is, they chose the status quo alternative in all eight choice situations. Table 1 summarises the reasons given by serial non-participants for not enrolling in the AES. The majority of the respondents (59 out of 67) stated a single reason. Of these respondents, 32 gave a reason related to opposition to the attributes, thus they were classified as VHT. These respondents stated reasons such as rejecting adoption of cover crops (attribute CCAR), non-attractiveness of the monetary incentive offered (attribute PAYM), and not wanting to be monitored (attribute MONI) ${ }^{6}$. Because all of the proposed AES alternatives included the use of cover crops (at $25 \%$ or at $50 \%$ ), cover crops adoption can represent a hurdle for AES participation. The choices of the farmers who generally rejected the use of cover crops therefore clearly reflect discontinuous preferences. Additionally, there were seven respondents who stated protest reasons other than opposition to the attributes, and are thus considered to be protesters.

The protest-related reasons mainly indicated negative attitudes towards the AES offered and, to a lesser extent, no reason/no response. In particular, many respondents generally rejected the idea of a multi-annual payment conditional on implementing additional management measures $(\mathrm{N}=17)$. The specific reasons included considering $A E S$ to be unnecessary and a nuisance, mostly related to simply opposing to the objective of the scheme of provision of environmental goods (as underscored by Christensen et al., 2011), but also complaints about the level of bureaucracy involved $(\mathrm{N}=3)$, and lack of trust in the public institutions administering AES $(\mathrm{N}=1)$ (mirroring the protest explanation of Lienhoop and Brouwer, 2015). Twelve respondents did not consider participation in AES to be an option for their small farms (consistent with Amigues et al., 2002), with seven of them stating other protest reason/s in addition to this. Two respondents expressed disapproval of any kind of subsidy, while nine respondents were not willing to provide reasons for serial nonparticipation, or declined a response (falling within the category no reason/no response, which is indicative of protest response as suggested by Amigues et al. 2002, and Barr and

\footnotetext{
${ }^{6}$ The specific reasons listed here result from qualitative information gathered by the interviewers.
} 
Mourato 2014). All of the above responses are of protest nature, because the interviewee is justifying his/her choices not on the basis of their preferences with regards to alternatives, attributes and levels presented in the choice tasks. All these reasons suggest that they were not willing to make trade-offs (Lusk et al., 2006) and hence state their true preferences towards the AES offered.

Table 1

Reasons for serial non-participation

\begin{tabular}{lccc}
\hline \multicolumn{1}{c}{ Reasons } & Protesters & $\begin{array}{c}\text { Very high } \\
\text { takers (VHT) }\end{array}$ & $\begin{array}{c}\text { Serial non- } \\
\text { participants }\end{array}$ \\
\hline $\begin{array}{l}\text { Non-protest reasons } \\
\quad \text { Opposition to attributes }\end{array}$ & 7 & 32 & 39 \\
$\begin{array}{l}\text { Protest reasons } \\
\quad \text { Rejecting the idea of a complementary }\end{array}$ & 17 & - & 17 \\
$\quad$ environmental subsidy & & & \\
$\quad$ Too much bureaucracy & 3 & - & 3 \\
$\quad$ Lack of trust in public institutions & 1 & - & 1 \\
$\quad$ AES not an option (small farms) & 12 & - & 12 \\
$\quad$ Disapproval of any kind of subsidy & 2 & - & 2 \\
$\quad$ No reason given & 1 & - & 1 \\
$\quad$ Response declined & 8 & - & 8 \\
\hline One reason given & 27 & 32 & 59 \\
Two or more reasons given & 8 & - & 8 \\
Total & 35 & 32 & 67 \\
\hline
\end{tabular}

Results of willingness to accept models

Table 2 shows the results of the RPL models in WTA space for the three samples: no serial non-participants excluded (Total), protesters excluded (No_protest), and all serial nonparticipants excluded (Participants). The three models are highly significant and goodness-offit indicators are favourable (pseudo- $R^{2}>0.43$ ). All attribute parameters are highly significant $\left(0.1 \%\right.$ level or lower) and have the expected sign. The parameter of the constant $\left(\mathrm{ASC}_{\mathrm{sQ}}\right)$ is negative and significantly different from zero. If a behavioural interpretation was applied, farmers would waive some of the compensation associated with AES participation for reasons that are unconnected to the scheme's specific attributes. However, it is also likely that the negative sign simply implies that, for a considerable number of the respondents, the expected benefits of scheme participation at the lowest compensation level ( $€ 100 /$ ha) outweigh expected cost of participation. The 'error component' is significant in each sample and decreases in magnitude when removing serial non-participants. This indicates that the error 
component is efficient in capturing the 'status quo effect' induced by serial non-participation (Scarpa et al., 2005). Results of models without the error component (not reported here, but available on request) confirm this finding.

Table 2

Random Parameter Logit model in WTA-space

\begin{tabular}{|c|c|c|c|c|c|c|}
\hline & \multicolumn{2}{|c|}{ Total } & \multicolumn{2}{|c|}{ No_Protest } & \multicolumn{2}{|c|}{ Participants } \\
\hline & Coef. & S.E. & Coef. & S.E. & Coef. & S.E. \\
\hline \multicolumn{7}{|l|}{ Mean } \\
\hline CCAR ( $1 \%$ of CCAR) & 0.078 & 0.002 & 0.067 & 0.002 & 0.073 & 0.004 \\
\hline CCMA (CCMA-Constr=1) & 1.800 & 0.050 & 1.770 & 0.077 & 1.830 & 0.107 \\
\hline EFA ( $1 \%$ of EFA) & 0.760 & 0.020 & 0.871 & 0.041 & 0.838 & 0.048 \\
\hline COLLE (Collective part. $=1$ ) & 1.230 & 0.050 & 1.150 & 0.075 & 1.440 & 0.100 \\
\hline MONI (1\% of farms monitored) & 0.014 & 0.002 & 0.013 & 0.003 & 0.018 & 0.005 \\
\hline PAYM & 1.120 & 0.120 & 1.440 & 0.174 & 0.975 & 0.154 \\
\hline $\mathrm{ASC}_{\mathrm{SQ}}$ & -0.693 & 0.085 & -0.800 & 0.104 & -1.240 & 0.169 \\
\hline \multicolumn{7}{|c|}{ Standard deviation of random parameters } \\
\hline CCAR & 0.112 & 0.003 & 0.110 & 0.004 & 0.094 & 0.006 \\
\hline CCMA & 2.040 & 0.044 & 2.150 & 0.081 & 2.000 & 0.098 \\
\hline EFA & 0.785 & 0.014 & 0.931 & 0.029 & 0.944 & 0.062 \\
\hline COLLE & 1.910 & 0.062 & 1.640 & 0.064 & 1.710 & 0.190 \\
\hline MONI & 0.025 & 0.003 & 0.010 & 0.003 & 0.016 & 0.005 \\
\hline PAYM & 1.610 & 0.126 & 1.560 & 0.185 & 1.190 & 0.157 \\
\hline $\mathrm{ASC}_{\mathrm{sQ}}$ & 0.891 & 0.057 & 0.704 & 0.028 & 1.050 & 0.070 \\
\hline Error component & 6.490 & 0.905 & 3.480 & 0.450 & 1.780 & 0.374 \\
\hline Log-likelihood (LL) & -1460.3 & & -1382.0 & & -1307.8 & \\
\hline McFadden Pseudo- $R^{2}$ & 0.492 & & 0.462 & & 0.428 & \\
\hline Observations & 327 & & 292 & & 260 & \\
\hline
\end{tabular}

Note: All the parameters and std. dev. are different from zero at $0.1 \%$ significance level. The monetary attribute has been scaled (100:1) and the sign has been changed to directly yield positive values that reflect farmers' WTA for a change in the attributes.

The resulting mean marginal WTA estimates are shown in Table 3, which also highlights significant differences between the samples. The exclusion of protesters and VHT has a significant effect on marginal WTA estimates for three out of the five attributes: CCAR, EFA and COLLE. However, there is no clear directional trend in differences between the three samples. We also report WTA equivalents related to the $\mathrm{ASC}_{\mathrm{sQ}}$ estimates, with Total and No_protest samples showing significantly higher values (€-69.3/ha and $€-80.0 /$ ha, 
respectively) than the Participants sample ( $€-124.0 /$ ha), suggesting that consideration of serial non-participation may have a large effect on total WTA estimates.

Table 3

Mean marginal willingness to accept (WTA) in $€ /$ ha

\begin{tabular}{|c|c|c|c|c|c|c|}
\hline \multirow[b]{2}{*}{ Attributes } & \multirow[b]{2}{*}{ Total } & \multirow[b]{2}{*}{ No_Protest } & \multirow[b]{2}{*}{ Participants } & \multicolumn{3}{|c|}{ Statistical differences } \\
\hline & & & & $\begin{array}{c}\text { Total- } \\
\text { No_Protest }\end{array}$ & $\begin{array}{c}\text { Total- } \\
\text { Participants }\end{array}$ & $\begin{array}{l}\text { No_Protest- } \\
\text { Participants }\end{array}$ \\
\hline \multirow{2}{*}{$\begin{array}{l}\text { Cover crops area } \\
\text { (1\% of CCAR) }\end{array}$} & 7.8 & 6.7 & 7.3 & $* * *$ & & \\
\hline & $(7.4 / 8.2)$ & $(6.3 / 7.1)$ & $(6.5 / 8.1)$ & & & \\
\hline \multirow{2}{*}{$\begin{array}{l}\text { Cover crops management } \\
\text { (CCMA-Constr=1) }\end{array}$} & 180.0 & 177.0 & 183.0 & & & \\
\hline & $(170.1 / 189.9)$ & $(161.6 / 192.4)$ & $(161.6 / 204.4)$ & & & \\
\hline \multirow{2}{*}{$\begin{array}{l}\text { Ecological focus areas } \\
\text { (1\% of EFA) }\end{array}$} & 76.0 & 87.1 & 83.8 & ** & & \\
\hline & $(72.0 / 80.0)$ & $(79.0 / 95.2)$ & $(74.2 / 93.4)$ & & & \\
\hline \multirow{2}{*}{$\begin{array}{l}\text { Collective participation } \\
(\text { COLLE }=1)\end{array}$} & 123.0 & 115.0 & 144.0 & & $*$ & ** \\
\hline & $(113.0 / 133.0)$ & $(100.0 / 130.0)$ & $(124.0 / 164.0)$ & & & \\
\hline \multirow{2}{*}{$\begin{array}{l}\text { Monitoring } \\
\text { (1\% of farms monitored) }\end{array}$} & 1.4 & 1.3 & 1.8 & & & \\
\hline & $(0.9 / 1.9)$ & $(0.8 / 1.8)$ & $(0.9 / 2.7)$ & & & \\
\hline \multirow[t]{2}{*}{$\mathrm{ASC}_{\mathrm{sQ}}$} & -69.3 & -80.0 & -124.0 & & ** & * \\
\hline & $(-86.3 /-52.3)$ & $(-100.8 /-59.2)$ & $(-157.8 /-90.2)$ & & & \\
\hline
\end{tabular}

Note: All WTA estimates are different from zero at the $0.1 \%$ significance level. ${ }^{*},{ }^{* *}$, and ${ }^{* * *}$ reflect statistical differences at $5 \%, 1 \%$, and $0.1 \%$ levels respectively -resulting from the Poe et al. (2005) test.

This is confirmed by the results of total WTA estimates for all possible combinations of attributes into AES alternatives reported in Table S2.1 (see Appendix S2). Total WTA varies remarkably depending on whether protesters and VHT are included in the sample or not. In particular, 31 out of the total of 32 AES alternatives show significant differences between the three samples (at $5 \%$ level). The highest estimate is always found for the Total sample, while the lowest estimate is always found for the Participants sample. In 24 and 17 out of the cases, removing those respondents identified as protesters (No_protest) results in significantly higher estimates compared to Total and significantly lower estimates compared to Participants, respectively. On average across all 32 AES alternatives, total WTA is $€ 280.3 /$ ha for Total, €250.0/ha for No_protest, and €222.3/ha for Participants. The order of magnitude of the estimates is in line with AES previously and currently implemented in olive growing in the region. A good example is scenario SC2, whose attribute levels correspond to the currently implemented AES. AES payments are $€ 145.3-174.7 /$ ha, set based on government's estimates of the olive growers' income forgone (Junta de Andalucía, 2015), which is very much on par with $€ 165.1 /$ ha of total WTA estimated for SC2 if protesters are excluded. 
While we have no data to estimate the actual opportunity costs of surveyed farmers, we calculated an approximate average value of $€ 230 /$ ha based on cost and productivity information reported for the olive sector in the region ${ }^{7}$ for the most stringent AES with individual participation (scenario SC16). This is lower than the estimate of total WTA (€396.8/ha, estimated if protesters are excluded) for that scenario. Various reasons can account for the difference. For example, transaction costs may be higher than assumed $(20 \%$ of costs of implementation and income forgone) for estimating average opportunity costs. It is also possible that non-profit-based motives are playing a large role for participation in AES. In addition, some respondents may have over-stated their compensation requirements in the choice experiment, although we have no evidence that farmers acted strategically.

\section{Results of the sample selection bivariate probit model}

The results of the sample selection bivariate probit model are shown in the Table 4. Because the rho coefficient is significant, residuals of the expressions explaining the two dependent variables are correlated. This suggests that the bivariate probit model is preferred over two separate probit models. The results of coefficients for covariates show that farm and farmer characteristics influence the likelihood of obtaining protest and VHT responses. In particular, farm size and farmers' age seem to be related to both types of responses. Small farms (less than 15 ha) and older farmers have a higher likelihood of both types of serial nonparticipation. With regards to protest responses, the type of olive grove, farmer's level of education, and her/his knowledge of AES currently implemented are also relevant determinants. Farmers without primary school education have a lower likelihood of acting according to their preferences in the valuation exercise (i.e. a higher likelihood of a protest response), while knowledge on current AES implemented or if the farm's main type is mountain olive groves is associated with a lower likelihood of showing protest responses. With regards to VHT responses, farm characteristics specifically related to the AES on offer and the attributes and levels included in it seem to determine farmer's decision on whether to participate or not (i.e. to be a participant or a VHT, respectively). Those farmers who comply with having $25 \%$ cover crops in line with attribute level CCAR $25 \%$, and those who perceive

\footnotetext{
${ }^{7}$ We therefore estimated average opportunity costs based on Rodríguez-Lizana et al. (2007) and Gómez-Limón and Arriaza (2011), assuming transaction costs of $20 \%$. Collecting reliable information on actual opportunity costs in the survey was not practicable. Therefore, this estimate should be treated with caution.
} 
the use of cover crops as economically beneficial, have a higher likelihood of participating (lower likelihood of being a VHT). The significant coefficients for the constants imply that there is unobserved heterogeneity which affects the decision of whether to protest or not (dependent variable Y1), and whether to participate or not (dependent variable Y2).

Table 4

Sample Selection Bivariate Probit model to explain protest, very high takers and participants' decisions

\begin{tabular}{llcc}
\hline Decision & \multicolumn{1}{c}{ Variable [acronym] } & Coef. & S.E. \\
\hline Y1 & Constant & $2.725^{* * *}$ & 0.634 \\
& Olive tree area below 15 ha [Oliarea15] & $-0.545^{* *}$ & 0.253 \\
& Farmer's age [Age] & $-0.023^{* *}$ & 0.011 \\
& Farmer did not go to school [Noeduca] & $-0.700^{* *}$ & 0.275 \\
& Farmer knows current AES implemented [KnowAES] & $0.590^{*}$ & 0.305 \\
& Main type of olive groves in the farm: Mountain olive groves [SysMOG] & $0.694^{* *}$ & 0.338 \\
\hline Y2 & Constant & $1.485^{* * *}$ & 0.560 \\
& Olive tree area below 15 ha [Oliarea15] & $-0.638^{* *}$ & 0.311 \\
& Farmer age [Age] & $-0.017^{*}$ & 0.010 \\
& Farmers complies with CCAR-25\% [CoCCAR25\%] & $0.664^{* *}$ & 0.299 \\
& Perception of cover crops as economically beneficial [PCCbenef] & $0.343^{* * *}$ & 0.083 \\
\hline Rho & & $-0.994^{* * *}$ & 0.059 \\
\hline
\end{tabular}

Log-likelihood function=-159.82; Observations: 324.

Note: Decisions: Y1 (0/1), Protest/Non protest; if Y1=1, Y2, Participation/Non participation (i.e. VHT) (1/0). All variables are dichotomous except PCCbenef, which is an ordinal scaled Likert scale variable (5 representing "Absolutely agree" with the statement that cover crops are economically beneficial for the farm in the long term), and Age (years). ${ }^{*},{ }^{* *}$, and ${ }^{* * *}$ reflect significance at $10 \%, 5 \%$, and $1 \%$ levels respectively.

This analysis is complemented with our on-line Appendix S3, which provides a comprehensive summary of the characteristics of the three groups of farmers (Protesters, Very high takers, and Participants), and reports the differences between the groups. Apart from those characteristics included in the bivariate probit model (Table 4), some characteristics are common to Protesters and VHT (more frequent use of conventional techniques, greater share of family labour, lower professional training), while others appear to be group specific. In particular, very high takers have less cover crop area, and perceive economic benefits from the use of cover crops and environmental benefits from EFA to be lower. Interestingly, fewer protesters claim membership to farmer unions, while they spend a lower share of their labour time on the farm.

These findings show that protesters and VHT clearly differ from participants in that they show characteristics that have previously been found to negatively affect AES uptake 
(Siebert et al., 2006; Uthes and Matzdorf, 2013). This includes farm and farmer characteristics, especially smaller farm size and older farmers, but also other characteristics (e.g. greater share of family labour, more frequent use of conventional techniques, greater additional effort implied by participation based on farmers' status quo). The differences between Protesters and VHT (especially regarding the use and perception of agri-environmental management practices) are in line with concerns about cover crops and EFA attributes raised by VHT when stating reasons for serial non-participation, as opposed to protesters, who objected to AES participation for reasons unrelated to the scheme specification.

\section{Discussion}

\section{Identifying protest responses}

Three general categories typically relate to protest responses in stated preference studies: i) respondents' attitudes towards the good at hand (e.g. dislike of the good under study, information inquiry); ii) the non-acceptance of the valuation approach (mainly critique of the method including objections to the payment vehicle, and fairness and ethical concerns); and iii) no reason/no response (Halstead et al., 1992; Jorgensen et al., 1999; Groothuis and Whitehead, 2002; Bateman et al., 2002; Meyerhoff and Liebe, 2006; Dziegielewska and Mendelsohn, 2007; Brouwer and Martín-Ortega, 2012). Protesters in our case study fall primarily in the category of respondents' attitude to the good at hand and no reason/no response. The absence of protest beliefs related to non-acceptance of the valuation approach may reflect the fact that Andalusian olive growers (as many other EU farmers) are used to choosing among different types of policy schemes. Similar to Christensen et al. (2011) we particularly find respondents showing disapproval to the type and objective of the scheme offered. This may not reflect rational utility maximising behaviour (especially concerning profits) as assumed in choice experiments as respondents categorically deny making tradeoffs between costs and benefits of scheme participation due to negative attitudes towards the schemes. Responses falling into the category of no reason/no response are difficult to interpret. No response/no reason may reflect either disinterest or lack of understanding, but we did not collect information to document the motives behind this category. 
Impact of protest responses on willingness to accept estimates

Our results clearly suggest that the inclusion/exclusion of serial non-participants (protesters and VHT) in the analysis strongly impacts WTA estimates. Three out of five attributes show significant differences in WTA. In terms of absolute magnitude, however, differences are most pronounced for estimates of total WTA, which are of particular relevance for understanding compensation requirements for participation in incentive-based schemes. Our results therefore suggest that protest responses should be identified and subsequently removed from further analysis, as with WTP studies (Barrio and Loureiro, 2013). Identification of protesters implies distinguishing them from VHT respondents. Excluding VHT in addition to protesters can result in significantly lower WTA estimates, which is clearly undesirable given that their compensation requirements are actually greater than the highest compensation level offered. Handling protest responses when analysing environmental providers' preferences towards incentive-based schemes

Since the impact of serial non-participation (either related to protesters or VHT) can be substantial, researchers should ideally attempt to avoid its occurrence ex ante. Therefore, we discuss some potential ex ante measures.

First, the design of the non-monetary attribute can affect the share of protest response and VHT. For example, many farmers in our analysis perceived constraints in how to manage cover crops to be very restrictive. While this is reflected by a high WTA for schemes that include such attribute levels, it can also increase the incidence of protest responses. This is the case if farmers are generally opposed to governments' proposed incentive-based schemes that contain unacceptable elements. Since perceptions of unnecessarily restrictive or unacceptable conditions depend on context, it is important to fully understand the proposed changes. If deviations of proposed changes from the status quo are substantial for some farmers, they may well protest that the proposed scheme is unrealistic. It follows that the 'lowest' attribute levels should be set to represent small to moderate changes relative to the status quo.

As in WTP formats, the design of the monetary attribute is particularly important. Although to our knowledge the sensitivity of WTA estimates to the design of the payment vector has not yet been systematically investigated in a similar fashion as in WTP formats (e.g. Hanley et al., 2005; Carlsson and Martinsson, 2008; Mørkbak et al., 2010), the range of 
compensation levels are very likely to have an effect on WTA estimates and serial-nonparticipation. The choice of lowest and highest amounts of compensation offered could well be critical. The lowest and highest compensation amounts need to be set to capture the greatest part of the potential ES supply. If the lowest compensation amount offered is not rejected by most of the respondents, the utility associated with accepting less than the lowest amount offered will be captured by the ASC, and the coefficient of the monetary attribute and thus WTA estimates may be biased. The choice of the lowest compensation amount offered may also be related to range bias (Bateman et al., 2002), which would occur if ES providers' WTA is lower than the lowest compensation amount offered and imply that their stated WTA is greater than their true minimum WTA. The highest compensation amount offered may be chosen to be sufficiently high to allow providers with high compensation requirements to participate in the scheme. This would potentially reduce the incidence of serial-nonparticipation by VHT. However, because the upper boundary of WTA is not constrained and little is known about the thresholds levels of compensation required by VHT, there are tradeoffs between increasing the magnitude of the highest level of the monetary attribute and associated undesirable effects, especially inducing strategic response behaviour. High compensation levels may signal to ES providers that the budget available for the scheme is substantial and they may thus be inclined to 'overstate' their WTA (especially if they consider their responses to be consequential). In addition, very high compensation amounts offered may also cast doubt on the credibility of the proposed schemes. Pivoting the compensation levels around a maximum compensation requirement for participation in schemes similar to the one on offer may offer a way forward. Further research is needed on the design of the monetary attribute in this type of WTA studies. Apart from the levels of payments, researchers should provide deeper insights on how the design of the payment vehicle (for example, contract length, frequency and timing of payments, conditionality of payments depending on others' participation and/or compliance) affect ES providers' WTA. In addition, the effect of individuals' perceived consequentiality of the survey on WTA estimates needs further investigation.

Our guidelines for discriminating between protest responses and VHT have been useful, and may prove helpful in other WTA contexts as well (e.g. farm decision-making (Hudson and Lusk, 2004; Windle and Rolfe, 2005)). We recommend the inclusion of follow-up questions to elicit the reasons behind serial non-participation to allow ex post identification 
of protest respondents. However, while closed-ended questions can assist in a more standardised, systematic identification, they can also suggest protest beliefs to respondents that they would otherwise not have considered. To avoid such framing effects, open-ended debriefing questions, followed by a clarification through the interviewer (in face-to-face surveys) using a pre-defined list of reasons for serial non-participation may be preferable. In mail or online surveys, a single-response closed-ended question could ask the respondent to choose the option that best represents her/his beliefs from a list of VHT and protest beliefs (or to rank them), perhaps using the reasons advanced in our study as a benchmark. More systematic analysis of protest attitudes and motives, for example along the line of Meyerhoff and Liebe (2006) in the context of WTP, would be clearly desirable for WTA studies.

\section{Conclusions}

The problem of protest responses in stated preference surveys remains contested in the environmental valuation literature, both on the demand side and the supply side. To our knowledge, this is the first study that provides a comprehensive survey and analysis concerning the identification and treatment of protest responses for supply side assessments. Focusing on an increasing number of choice experiments aimed at estimating environmental service providers' WTA to participate in incentive-based schemes, we demonstrate the relevance of considering serial non-participation and especially protest responses. Based on our empirical findings, we recommend routinely identifying protest responses and subsequently excluding them from analysis used to derive WTA estimates. Additionally, protest responses must be distinguished from serial non-participation by 'very high takers', that is, respondents who require high compensation amounts in return for scheme participation. In contrast to protest respondents, very high takers reveal their true preferences by opting for non-participation in all choice situations, so they should be included in the analysis of WTA. We propose a general framework to distinguish between protesters and very high takers, but further research is needed on the reasons for protest responses.

If protest responses are not identified, and consequently included in the analysis, researchers risk deriving biased estimates of ES providers' minimum compensation requirements. This can result in inappropriate budget allocation for the implementation of the related incentive-based schemes, ultimately also affecting ES provision. In some previous studies very high takers were also excluded from the analysis. Our results show that this may 
also provide erroneous signals to policy makers, because implementation budgets may be set too low.

We strongly recommend that researchers include follow-up questions to elicit the reasons behind serial non-participation in order to allow ex post identification of protest respondents. We report several beliefs stated by ES providers that are likely reflecting protest responses that can be adjusted to different study contexts and samples. Because options to deal with serial non-participation ex post are limited, we recommend developing ex ante measures in the research design to mitigate serial non-participation especially by reducing the amount of very high takers. In this respect, a better understanding of the role of the design of scheme attributes is needed.

\section{References}

Adamowicz, W., Boxall, P., Williams, M. and Louviere, J. 'Stated preference approaches for measuring passive use values: Choice experiments and contingent valuation', American Journal of Agricultural Economics, Vol. 80(1), (1998) pp. 64-75.

Amigues, J.P., Boulatoff, C., Desaigues, B., Gauthier, C. and Keith, J.E. 'The benefits and costs of riparian analysis habitat preservation: A willingness to accept/willingness to pay contingent valuation approach'. Ecological Economics, Vol. 43(1), (2002) pp. 17-31.

Arrow, K.J., Solow, R., Portney, P.R., Leamer, E.E., Radner, R. and Schuman, H. Report of the NOAA panel on contigent valuation (London, UK: Federal Register, 1993).

Barnes, A.P., Willock, J., Toma, L. and Hall, C. 'Utilising a farmer typology to understand farmer behaviour towards water quality management: Nitrate Vulnerable Zones in Scotland', Journal of Environmental Planning and Management, Vol. 54(4), (2011) pp. 477-494,

Barr, R.F. and Mourato, S. 'Investigating fishers' preferences for the design of marine payments for environmental services schemes', Ecological Economics, Vol. 108, (2014) pp. 91-103.

Barranco, D., Fernández-Escobar, R. and Rallo, L. El cultivo del olivo (Madrid: Mundi-Prensa and Junta de Andalucía, 2008).

Barrio, M. and Loureiro, M. 'The impact of protest responses in choice experiments: An application to a biosphere reserve management program', Forest Systems, Vol. 22(1), (2013) pp. 94-105.

Bateman, I.J., Carson, R.T., Day, B., Hanemann, M., Hanley, N., Hett, T., Jones-Lee, M., Loomes, G., Mourato, S., Ozdemiroglu, E., Pearce, D.W., Sugden, R. and Swanson, J. Economic valuation with stated preference surveys: A manual (Cheltenham, UK: Edward Elgar Publishing, 2002).

Beharry-Borg, N., Smart, J.C.R., Termansen, M. and Hubacek, K. 'Evaluating farmers' likely participation in a payment programme for water quality protection in the UK uplands', Regional Environmental Change, Vol. 13(3), (2013) pp. 633-647.

Broch, S.W. and Vedel, S.E. 'Using choice experiments to investigate the policy relevance of heterogeneity in farmer agri-environmental contract preferences', Environmental and Resource Economics, Vol. 51(4), (2012) pp. 561-581. 
Brouwer, R. and Martín-Ortega, J. 'Modeling self-censoring of polluter pays protest votes in stated preference research to support resource damage estimations in environmental liability', Resource and Energy Economics, Vol. 34(1), (2012) pp. 151-166.

Burton, R.B. 'Reconceptualising the 'behavioural approach' in agricultural studies: A sociopsychological perspective', Journal of Rural Studies, Vol. 20(3), (2004) pp. 359-371.

CAyP (Consejería de Agricultura y Pesca). El sector del aceite de oliva y de la aceituna de mesa en Andalucía (Seville, Spain: Junta de Andalucía, 2008).

Carlsson, F. and Martinsson, P. 'How much is too much? An investigation of the effect of the number of choice sets, context dependence and the choice of bid vectors in choice experiments' Environmental and Resource Economics, Vol. 40 (2), (2008) pp. 165-176.

Carson, R.T. and Groves, T. 'Incentive and informational properties of preference questions', Environmental and Resource Economics, Vol. 37(1), (2007) pp. 181-210.

Chouinard, H., Paterson, T., Wandschneider, P. and Ohler, A. 'Will farmers trade profits for stewardship? Heterogeneous motivations for farm practice selection', Land Economics, Vol. 84(1), (2008) pp. 66-82.

Christensen, T., Pedersen, A.B., Nielsen, H.O., Mørkbak, M.R., Hasler, B. and Denver, S. 'Determinants of farmers' willingness to participate in subsidy schemes for pesticide-free buffer zones-A choice experiment study', Ecological Economics, Vol. 70 (8), (2011) pp. 1558-1564.

Cooper, J.C. 'Combining actual and contingent behavior data to model farmer adoption of water quality protection practices', Journal of Agricultural and Resource Economics, Vol. 22(1), (1997) pp. 30-43.

Dziegielewska, D. and Mendelsohn, R. 'Does "No" mean "No"? A protest methodology'. Environmental and Resource Economics, Vol. 38(1), (2007) pp. 71-87.

Espinosa-Goded, M., Barreiro-Hurlé, J. and Ruto, E. 'What do farmers want from agrienvironmental scheme design? A choice experiment approach', Journal of Agricultural Economics, Vol. 61(2), (2010) pp. 259-273.

Falconer, K. 'Farm-level constraints on agri-environmental scheme participation: A transactional perspective', Journal of Rural Studies, Vol. 16(3), (2000) pp. 379-394.

Ferreira, S. and Gallagher, L. 'Protest responses and community attitudes toward accepting compensation to host waste disposal infrastructure', Land Use Policy, Vol. 27(2), (2010) pp. 638-652.

Gasson, R. 'Goals and values of farmers', Journal of Agricultural Economics, Vol. 24 (3), (1973) pp. 521-542.

Gómez-Limón, J.A. and Arriaza, M. Evaluación de la sostenibilidad de las explotaciones de olivar en Andalucía (Málaga, Spain: Analistas Económicos de Andalucía, 2011).

Greene, W.H. Econometric analysis (Upper Saddle River, NJ: Prentice Hall, 2003).

Groothuis, P.A. and Whitehead, J.C. 'Does don't know mean no? Analysis of 'don't know' responses in dichotomous choice contingent valuation questions', Applied Economics, Vol. 34(15), (2002) pp. 1935-1940.

Halstead, J.M., Luloff, A. and Stevens, T.H. 'Protest bidders in contingent valuation', Northeastern Journal of Agricultural and Resource Economics, Vol. 21(2), (1992) pp. 160169.

Hanemann, W.M. 'Welfare evaluations in contingent valuation experiments with discrete responses', American Journal of Agricultural Economics, Vol. 66(3), (1984) pp. 332-341.

Hanley, N., Adamowicz, W. and Wright, R.E. 'Price vector effects in choice experiments: An empirical test', Resource and Energy Economics, Vol. 27(3), (2005) pp. 227-234. 
Horne, P. 'Forest owners' acceptance of incentive based policy instruments in forest biodiversity conservation - A choice experiment based approach', Silva Fennica, Vol. 40(1), (2006) pp. 169-178.

Hudson, D. and Lusk, J. 'Risk and transactions cost in contracting: Results from a choice-based experiment', Journal of Agricultural and Food Industrial Organization, Vol. 2(1), (2004) Article 2.

Hynes, S. and Garvey, E. 'Modelling farmers' participation in an agri-environmental scheme using panel data: An application to the Rural Environment Protection Scheme in Ireland', Journal of Agricultural Economics, Vol. 60(3), (2009) pp. 546-562.

Jorgensen, B.S., Syme, G.J., Bishop, B.J. and Nancarrow, B.E. 'Protest responses in contingent valuation', Environmental and Resource Economics, Vol. 14(1), (1999) pp. 131-150.

Junta de Andalucía. Programa de Desarrollo Rural de Andalucía 2014-2020 (Seville, Spain: Junta de Andalucía, 2008).

Kuhfuss, L., Préget, R., Thoyer, S. and Hanley, N. 'Nudging farmers to enrol land into agrienvironmental schemes: The role of a collective bonus', European Review of Agricultural Economics, (2015) In press.

Layton, D. and Siikamäki, J. 'Payments for Ecosystem Services programs: Predicting landowner enrollment and opportunity cost using a beta-binomial model', Environmental and Resource Economics, Vol. 44(3), (2009) pp. 415-439.

Lienhoop, N. and Brouwer, R. 'Agri-environmental policy valuation: Farmers' contract design preferences for afforestation schemes', Land Use Policy, Vol. 42, (2015) pp. 568-577.

Lusk, J.L., Traill, W.B., House, L.O., Valli, C., Jaeger, S.R., Moore, M., and Morrow, B. 'Comparative advantage in demand: Experimental evidence of preferences for genetically modified food in the United States and European Union', Journal of Agricultural Economics, Vol. 57(1), (2006) pp. 1-21.

Matta, J.R., Alavalapati, J. R. R. and Mercer, D. E. 'Incentives for biodiversity conservation beyond the best management practices: Are forestland owners interested?', Land Economics, Vol. 85(1), (2009) pp. 132-143.

Meyerhoff, J. and Liebe, U. 'Protest beliefs in contingent valuation: Explaining their motivation', Ecological Economics, Vol. 57(4), (2006) pp. 583-594.

Meyerhoff, J. and Liebe, $U$. 'Determinants of protest responses in environmental valuation: A meta-study', Ecological Economics, Vol. 70(2), (2010) pp. 366-374.

Meyerhoff, J., Bartczak, A. and Liebe, U. 'Protester or non-protester: A binary state? On the use (and non-use) of latent class models to analyse protesting in economic valuation', Australian Journal of Agricultural and Resource Economics, Vol. 56(3), (2012) pp. 438-454.

Meyerhoff, J., Mørkbak, M.R. and Olsen, S.B. 'A meta-study investigating the sources of protest behaviour in stated preference surveys', Environmental and Resource Economics, Vol. 58(1), (2014) pp. 35-57.

Mørkbak, M. R., Christensen, T. and Gyrd-Hansen, D. 'Choke price bias in choice experiments', Environmental and Resource Economics, Vol. 45(4), (2010) pp. 537-551.

Mulatu, D.W., Van Der Veen, A. and van Oel, P.R. 'Farm households' preferences for collective and individual actions to improve water-related ecosystem services: The Lake Naivasha basin, Kenya', Ecosystem Services, Vol. 7, (2014) pp. 22-33.

Pannell, D.J. 'Public benefits, private benefits, and policy mechanism choice for land-use change for environmental benefits', Land Economics, Vol. 84(2), (2008) pp. 225-240. 
Peterson, J.M., Smith, C.M., Leatherman, J.C., Hendricks, N.P. and Fox, J.A. 'Transaction costs in payment for environmental service contracts', American Journal of Agricultural Economics, Vol. 97(1), (2015) pp. 219-238.

Poe, G.L., Giraud, K.L. and Loomis, J.B. 'Computational methods for measuring the difference of empirical distributions', American Journal of Agricultural Economics, Vol. 87(2), (2005) pp. 353-365.

Rodríguez-Lizana, A., Ordóñez-Fernández, R., and Gil-Ribes, J. Cubiertas vegetales en olivar (Seville, Spain: Junta de Andalucía, 2007).

Scarpa, R., Ferrini, S. and Willis, K.G. 'Performance of error component models for status-quo effects in choice experiments' in: R. Scarpa and A. Alberini (eds.) Applications of simulation methods in environmental and resource economics (Dordrecht, The Netherlands: Springer, 2005)

Schilizzi, S. and Latacz-Lohmann, U. 'Incentivizing and tendering conservation contracts: The trade-off between participation and effort provision', Land Economics, Vol. 92(2), (2016) pp. 273-291.

Siebert, R., Toogood, M. and Knierim, A. 'Factors affecting European farmers' participation in biodiversity policies. Sociologia Ruralis, Vol. 46(4), (2006) pp. 318-340.

Söderberg, M. and Barton, D.N. 'Marginal WTP and distance decay: The role of 'protest' and 'true zero' responses in the economic valuation of recreational water quality', Environmental and Resource Economics, Vol. 59(3), (2014) pp. 389-405.

Stoate, C., Baldi, A., Beja, P., Boatman, N.D., Herzon, I., van Doorn, A., de Snoo, G.R., Rakosy, L. and Ramwell, C. 'Ecological impacts of early 21st century agricultural change in Europea review', Journal of Environmental Management, Vol. 91(1), (2009) pp. 22-46.

Strazzera, E., Genius, M., Scarpa, R. and Hutchinson, G. 'The effect of protest votes on the estimates of WTP for use values of recreational sites', Environmental and Resource Economics, Vol. 25(4), (2003) pp. 461-476.

Street, D.J. and Burgess, L. The construction of optimal stated choice experiments: Theory and methods (Hoboken, New Jersey: John Wiley and Sons, 2007).

Train, K. Discrete choice methods with simulation (Cambridge, UK: Cambridge University Press, 2003).

Train, K. and Weeks, M. 'Discrete choice models in preference space and willingness-to-pay space' in: R. Scarpa and A. Alberini (eds.) Applications of simulation methods in environmental and resource economics (Dordrecht, The Netherlands: Springer, 2005)

Uthes, S. and Matzdorf, B. 'Studies on agri-environmental measures: A survey of the literature', Environmental Management, Vol. 51(1), (2013) pp. 251-266.

Villanueva, A.J., Gómez-Limón, J.A., Arriaza, M. and Nekhay, O. 'Analysing the provision of agricultural public goods: The case of irrigated olive groves in southern Spain', Land Use Policy, Vol. 38, (2014) pp. 300-313.

Villanueva, A.J., Gómez-Limón, J.A., Arriaza, M. and Rodríguez-Entrena, M. 'The design of agrienvironmental schemes: Farmers' preferences in southern Spain', Land Use Policy, Vol. 46, (2015) pp. 142-154.

Windle, J. and Rolfe, J. 'Diversification choices in agriculture: A choice modelling case study of sugarcane growers', Australian Journal of Agricultural and Resource Economics, Vol. 49(1), (2005) pp. 63-74. 